\title{
NORBERTO BOBBIO: LA RESPONSABILIDAD DEL INTELECTUAL
}

\author{
Elías Díaz \\ Universidad Autónoma de Madrid
}

\begin{abstract}
RESUMEN. En este artículo se estudia la visión teórica del intelectual en el pensamiento de Norberto Bobbio. En este pensamiento se distingue el modelo de intelectual, caracterizado por la duda (metódica), la razón (crítica) y el diálogo (libre y público), del intelectual real, caracterizado por su labor de suministrar criterios-guía orientados a repercutir en la realidad social. Bobbio reivindica, sin dogmatismos, la dimensión normativa de la noción de intelectual: la tarea específica del mismo será la de prescribir valores.
\end{abstract}

\begin{abstract}
In this article the theoretical vision of the intellectual in Norberto Bobbio's thinking is studied. He makes a distinction between the model intellectual, who is characterized by doubt (methodical), reason (critical) and dialogue (free and public), and the real intellectual, characterized by the function he carries out of providing guiding-criteria, which are aimed at having an impact on social reality. Bobbio defends, without dogmatism, the normative dimension of the concept of the intellectual: their specific function is that of establishing values.
\end{abstract}




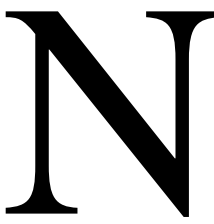

orberto Bobbio -aquí le estamos recordando por ello- es un muy eximio, agudo e influyente filósofo del derecho e igualmente filósofo de la política: a mi juicio, en ambas zonas, uno de los más destacados de todo el siglo XX. Pero a la vez, o mejor dicho unido en profundidad a ello, los caracteres de su obra y de su vida concuerdan siempre con las que son propias de alguien a quien puede y debe identificarse como un intelectual. Y él mismo se consideró siempre así. En cuanto tal, en ese su autorreflexivo ámbito, de puesta en cuestión de su tarea especulativa, de su "autoconciencia” sobre el sentido social de su labor filosófica (a diferencia del filósofo “académico”), es en el que de modo preferente va a ser considerado ahora en estas breves notas mías. Sirvan al menos de modesta contribución a ese estudio más de fondo sobre su visión teórica de la tarea del intelectual que -en la laudatio para el Doctorado Honoris Causa del maestro turinés por la Universidad Autónoma de Madrid (Bobbio, los intelectuales y la política)- Alfonso Ruiz Miguel demandaba como necesario y, sin embargo, ausente junto a las otras investigaciones sobre las principales dimensiones del pensamiento de aquél ${ }^{1}$.

1.- En cuanto propuesta prescriptiva y optativa recordemos que Bobbio siempre ha preferido hablar, también respecto de sí mismo, en términos de intelectual responsable y no tanto de intelectual comprometido. La responsabilidad le parece, quizás con razón, un concepto con mayores implicaciones morales que el de compromiso -vocablo, no obstante, también utilizado por él y ambos situados en el mismo mundo de valores sociales-, entendido por lo general este último en forma de adhesiones políticas más estrictas y restrictivas. El intelectual es -se le exige ser- hombre de principios, de creencia en las convicciones pero también -por resituarlo en la dicotomía weberiana, reasumiendo a Kant y a Mill- es, a la vez, de manera muy especial, hombre de responsabilidades (ante si mismo y ante los demás), es decir de preocupación por los resultados y las consecuencias de sus propuestas. El intelectual no es, ni debe ser, un irresponsable; como tampoco, se añadirá, el político carece sin más de principios de (buenas o malas) convicciones.

\footnotetext{
${ }^{1}$ Este texto de Alfonso Ruiz Miguel se ha publicado solamente en su traducción italiana (de Giuseppe Lorini) en la obra colectiva preparada por Luigi Ferrajoli y Paolo di Lucia, Diritto e democrazia nella filosofia di Norberto Bobbio, Turín, Giappichelli Editore, 1999; cfr. aquí, entre otras, pp. 257-258. En su libro Norberto Bobbio: Un hombre fiero y justo (Fondo de cultura Económica, Santiago de Chile, 2005) el profesor Agustín Squella resalta (p. 17) el testimonio, con un cierto embarazo, de aquél: “mi auténtica profesión ha sido la de un intelectual”.
} 
Bobbio advertirá, sin embargo, que el nexo entre principios, (o fines) propugnados y sus derivaciones y conclusiones fácticas no es siempre absolutamente claro, univoco y directo. No existe en todos los casos, ni siquiera en la mayoría de ellos, una forma de causalidad inmediata y mecánica sino más bien mediada y mutada por diferentes factores que, a lo largo del proceso, operan en mutua interrelación plural (dialéctica, diría el propio Bobbio de acuerdo con alguna de sus acepciones de ésta). Entre una concepción del mundo y las transformaciones de la sociedad en una u otra dirección -escribe aquél- se producen no pocas mediaciones: así, las introducidas por los seguidores de tal concepción, por sus diversas interpretaciones en las plurales escuelas o movimientos que de ahí puedan derivar, por las circunstancias de tiempo y de lugar, por la mayor o menor madurez de ellas, por los propios destinatarios del mensaje, etc. etc. No hay una sola respuesta cierta y segura en esa determinación de los resultados y responsabilidades respecto de los principios y las convicciones, señala Bobbio.

En esa difícil complejidad que caracteriza toda realidad histórica y social, la función muy propia del intelectual -tanto para poder comprender como para intentar transformar- es (debe ser, plano prescriptivo) la de trabajar como mediador, tanto en la conformación y delimitación de principios como entre todas esas instancias reales y propuestas interpretativas. Bobbio dirá de sí mismo no haber nunca renunciado al tipo ideal del "intelectual mediador”, cuyo método de acción es el diálogo racional, donde los interlocutores discuten presentando argumentos razonados y cuya virtud esencial es la tolerancia. En él, mediación y mediador no significan para nada situarse fuera o por encima del problema, del conflicto (au dessus de la mêlée); no son mero eclecticismo o pacificación a cualquier precio, ni -asunto decisivo- exacta adiáfora equidistancia entre no importa que tipo de doctrina u opinión, sino -según sus propias palabras-, comprensión de las razones del otro, búsqueda de los puntos que unen más que de los que separan.

En todos sus escritos sobre estas cuestiones, y en sus actitudes prácticas a lo largo de toda su vida, Bobbio ha pretendido y logrado evitar respectivamente la evasión y la reducción de la función del intelectual que se concreta en esos dos bien conocidos y, a su vez, opuestos modelos también denominados como intelectual apolítico y como intelectual orgánico. Resume así, en términos tanto descriptivos como prescriptivos, las tres posiciones posibles del intelectual ante la sociedad en -dice- estas tres fórmulas: "ni de aquí ni de allí; o de aquí o de allí; de aquí y de allí”: esta última, es evidente, es la suya. Con otras palabras, la primera posición (ni con unos ni con otros) es la de aquél que tiende siempre a lavarse las manos, a colocarse por encima o fuera del conflicto o, más duramente, a despreocuparse por completo de los problemas que puedan afectar a unos y a otros, es decir a todos 
menos a uno mismo: con esa actitud, autoreflexiva en cualquier caso, se sitúa casi en el límite negativo de lo que, ya hemos dicho, sería propiamente un intelectual: esa sería la diferencia con el filósofo puramente "académico”. La segunda posición (o con unos o con otros) es la del maniqueo que necesita siempre separar y optar entre quienes coloca irremediablemente o en las filas de los seguidores de la luz o en las filas de los seguidores de las tinieblas: es este en efecto un riesgo también de un cierto tipo de intelectual orgánico, especialmente en regímenes o partidos totalitarios para quienes “todo es política y la política lo es todo”. La tercera posición, la del intelectual mediador (“de aquí y de allí”) en la que Bobbio se reconoce, implica el diálogo con unos y con otros, la comprensión de sus respectivas razones, aunque no para nada el eclecticismo o la indiferencia o indefinición, que en definitiva llevaría casi a una versión más ilustrada de la primera posición. No, pues, neutralidad (ni con unos, ni con otros) sino casi podría decirse, rememorando a nuestro Miguel de Unamuno, “alterutralidad”: es decir, con unos y con otros (pero sin indiferentes equidistancias, advertiría yo, entre por ejemplo dictaduras y democracias), comprendiéndolos y -añadía el buen vasco- uniéndolos, fundiéndolos y hasta confundiéndolos. En más de una ocasión escribí y hablé con Norberto Bobbio (también con Renato Treves) acerca de esa hispano-italiana actitud de correlación entre intelectuales por lo demás tan diferentes.

Ante estos tan nobles y justificados objetivos de comprensión, mediación y argumentación que se propugnan como función del intelectual y de los que Bobbio jamás abjura, su moderado escepticismo (nunca, pues, contradictorio) y su controlado pesimismo (compatible con su iluminismo) introducen siempre la duda en cuanto a las posibilidades reales del cumplimiento de tal tarea y, aún más, sobre la influencia y eficacia social de ella. En el fondo y más radicalmente de lo que se trata es, pues, de la duda como cualidad que mejor identifica -dice- al hombre de razón. Frente a la apuesta fideista de Pascal -la extrema y más desesperada expresión del fideísmo- la duda metódica de Descartes constituye el origen de la ciencia (y la filosofía) moderna. El hombre de razón -señala Bobbio- no apuesta. El hombre de razón, cuando no dispone de pruebas, duda; e, incluso, será legítimo dudar, cuestionar y recelar, de las propias pruebas. Il dubbio e la scelta, "la duda y la elección” en su traducción española, es precisamente el título puesto por aquél, en 1993, a la recopilación de todos sus escritos sobre los intelectuales y el poder en la sociedad contemporánea. La duda lleva al diálogo. La primera expresión de "la política de la cultura”-denominación tan bobbiana- es el diálogo. Quien se instala en certezas dogmáticas, cree que puede prescindir del diálogo. En cambio, quien duda sabe que debe 
mantener siempre abierta la comunicación con los otros; y sabe que además debe optar, elegir. Con ello empieza en rigor la democracia ${ }^{2}$.

La duda (metódica), la razón (crítica), el diálogo (libre y público), incluso por tanto la genérica conclusión democrática, resultan ser así ingredientes que en mayor medida caracterizan al intelectual, tal y como se viene entendiendo este término -no sin variantes significativas- desde la Francia de finales del XIX: desde el affaire Dreyfus y el Manifeste des intellectuels firmado por ilustres escritores como, entre otros, Emile Zola, Anatole France o Marcel Proust. En líneas generales de ahí -y yendo más allá, de las mejores aportaciones de la Ilustración- derivaría, con las cautelas propias de estos más complejos tiempos, el modelo prescriptivo propuesto y propugnado por Norberto Bobbio (con el cual concuerdo) y, dentro de él, bajo esa forma específica y coherente del "intelectual mediador".

2.- Pero ese modelo ideal, con rasgos incluso utópicos (utopía racional), en cualquier caso modelo prescriptivo -y optativo, añade casi siempre aquél-, no le lleva en modo alguno a negar ese título de intelectual, en su dimensión descriptiva, a quienes no concuerdan con esos caracteres seleccionados en su opción, o con la interpretación que de los mismos allí se pueda haber hecho. Por decirlo de manera más clara y directa, para Bobbio el intelectual no es sólo y exclusivamente, según los términos convencionales, el hombre de ideas progresistas o de izquierdas (como algunos mantienen) sino asimismo aquél que suele ser calificado de conservador o de derechas. Y, en los límites (tesis por algunos muy debatida), también lo serían incluso quienes se pronuncian, hablan y escriben como enemigos de gentes, sociedades, instituciones, partidos o regímenes con idearios democráticos: es decir, quizás más ayer que hoy, escritores o filósofos que, bajo unos u otros alegatos, cuestionan y niegan el ejercicio de la pública (a veces hasta de la privada) libertad, defendiendo uniformes posiciones doctrinales de sentido dictatorial, absolutista o totalitario.

Esta actitud, extensiva y comprensiva, de Norberto Bobbio en cuanto a cuales sean los valores que caben en la descripción sociológica del intelectual, es decir, de cuales son los modos de intelectual realmente existentes, se conecta de modo expreso por él con la tipología reasumida por Theodor

\footnotetext{
${ }^{2}$ Norberto Bobbio, Il dubbio e la scelta. Intellettuali e potere nella societá contemporanea, Roma, La Nuova Italia Scientifica, 1993; las constantes referencias a su pensamiento en estas páginas mías proceden de esta recopilación (hay, como señalo, traducción española, Barcelona, Editorial Paidós por Carmen Revilla). Tras aquella, me parece que sólo tenemos un único y último artículo de Norberto Bobbio sobre directamente el tema de que aquí se trata: L’impegno dell'intellettuale ieri e oggi, publicado en "Rivista di Filosofia”, vol. LXXXVIII, n 1, abril de 1997.
} 
Geiger al diferenciar cuatro posibles actitudes generales del espíritu (de los intelectuales) en relación con el poder: a) primacía del espíritu sobre el poder; b) servidumbre del espíritu al poder; c) mediación entre espíritu y poder; d) crítica del poder. Y lo propio resulta de la establecida por Lewis A. Coser quien reagrupa dicha relación en las cuatro siguientes actitudes de los intelectuales según su posición: a) cuando ellos mismos están en el poder; b) cuando tratan de influir sobre el poder pero quedándose fuera de él; c) cuando aceptan que su tarea prioritaria es legitimar el poder; d) cuando critican y combaten al poder. A ellas añade Bobbio la que aquellos intelectuales que pretenden no tener ninguna relación con el poder. Se trata, como vemos, de una amplia y muy diversa tipología, en graduación teórica y práctica de quienes -aún en esa pluralidad de actitudes- se consideran y se han considerado como intelectuales por, repito, esa su mayor o menor autoreflexión sobre el significado de su trabajo en relación con la sociedad o, más directamente, con la política ${ }^{3}$.

En consonancia con ello, Bobbio insiste continuamente en la necesidad -así se está resaltando aquí- de evitar la confusión derivada de la superposición entre el "significado descriptivo neutral del término y sus diversos significados valorativos”. Con frecuencia, en efecto, al describir qué y quien sea intelectual se produce -rememoremos a Hume- una introducción subrepticia de una definición persuasiva: o sea, de una definición en la que se ineludiblemente vienen a atribuirse al intelectual -sigue Bobbio- caracteres moralmente positivos como -enumera él- la independencia de juicio, la valentía de las propias opiniones, el amor por la aventura espiritual, el gusto de la paradoja, la audacia de las ideas, el espíritu crítico, la propensión hacia la innovación y otros similares caracteres que -no olvidemos- aquí se reconocen como "moralmente positivos", es decir, adscritos a una personal idea prescriptiva del intelectual. Exigir, restringir por tanto, esos y otros similares rasgos valorativos para la definición descriptiva del intelectual -señala aquél- tendría como consecuencia expulsar de tal categoría a todos aquellos que, aún correspondiéndoles tal título por la función llevada a cabo, es decir por su consideración -incluso negativa- de la realidad social,

${ }^{3}$ Theodor Geiger, Aufgaben und Stellung der Intelligenz in der Gesellschaft (1949); Lewis A. Coser, Men of Ideas (1965), ambas citadas, como digo, por Bobbio. Añadiré por mi cuenta algunas otras obras que, en pluralidad de interpretaciones, pueden -a mi juicio- resultar de interés para este punto en que estamos pero también para otros de los considerados en estas páginas: Christophe Charle, Los intelectuales en el siglo XIX. Precursores del pensamiento moderno, Prólogo de Juan Pablo Fusi, Madrid, Ed. Siglo XXI, 2000; Anthony Phelan, El dilema de Weimar. Los intelectuales en la República de Weimar, Valencia, Edicions Alfons el Magnanim, 1990; Paul Johnson, Intellectuals, Londres, G. Weidenfeld and Nicolson, 1988; Russell Jacoby, The last Intellectuals. American Culture in the Age of Academe, Nueva York, Basic Book Publishers, 1987. 
no parezcan poseer esas cualidades imprescindibles a los ojos de quien les juzga con dicha medida. Concluye, por tanto, Bobbio que para un correcto planteamiento del problema en el plano de la descripción resulta oportuno acogerse al término en su uso más neutral, o sea ahora con independencia a esos efectos de cualquier juicio de valor.

Los intelectuales no constituyen una clase homogénea (cuestión que en otros tiempos dio lugar a no pocas polémicas), ni son nunca, salvo en el caso de las sociedades teocráticas, los depositarios de un único cuerpo de doctrina. Así -especifica Bobbio sobre esa pluralidad-, según las ideas que propugnan o por las cuales combaten, aquellos serían progresistas o conservadores, radicales o reaccionarios; según las ideologías que defienden, tendríamos libertarios o autoritarios, liberales o socialistas; según su propia actitud respecto de las ideas mismas que sostienen, les calificaríamos de escépticos o dogmáticos, de laicos o clericales. Ante tal evidencia, la consecuencia es que si se debiese decidir quienes son intelectuales no en base al significado descriptivo del término sino en base al significado valorativo, $\mathrm{y}$ por lo tanto se excluyesen recíprocamente los de cada diferente u opuesto grupo y orientación, el resultado sería que la clase lógica de los intelectuales -concluye Bobbio- acabaría por ser una clase vacía.

Mejor que una clase vacía -nadie sería intelectual desde la otra perspectiva- es preferible una clase no llena, sin embargo, de modo amorfo e indiferenciado cualquiera que sea su profesión y dedicación, pero sí compuesta por quienes poseen algo significativo en común para poder considerarse y ser considerados como intelectuales. La amplitud y extensión en aquél a la hora de definir y describir a los intelectuales en su pluralidad de fines y valores, se hace más restrictiva e intensiva cuando se les identifica por su función y profesión. En este sentido continúa sin duda teniendo utilidad, como inicial criterio diversificador, la dicotomía (sin absoluta escisión ni esencialista valoración) entre trabajo intelectual y trabajo manual: ello, por puesto, no afecta '-pienso- a que, una u otra categoría puedan (y quizás hasta deban) estar abiertas a fructíferas relaciones de conocimiento e intercambio. Y también es cierto que en nuestro tiempo, en las actuales formas de producción, y de organización social, no pocos sectores del tradicional trabajo manual se han ido haciendo cada vez más especializados, necesitados de mayores conocimientos técnicos (casi científicos), en cierto modo -diríamos- más intelectualizados. A ello habría que añadir tantas y tantas profesiones no manuales, sino por ejemplo empresariales, de gestión, burocráticas, de organización y administración o similares, también las denominadas profesiones liberales (todas más o menos en las viejas y nuevas clases medias), a las que sería difícil no reconocer el ejercicio de una actividad cercanas a un “trabajo intelectual”. Y, sin embargo, señala Bobbio, 
también sería difícil que a ellas se les incluyera sin más en lo que significa de modo más estricto el sustantivo “intelectual”: es decir -de esto estamos tratando- en lo que propiamente pensamos cuando hablamos de los intelectuales o personalmente de un intelectual, en cuanto cuestionamiento de alcance teórico, mayor o menor, sobre las implicaciones sociales de tal o cual profesión u ocupación.

Por ello diferencia siempre aquél a -dice- los que podemos llamar intelectuales en sentido estricto (el concepto de intelectual como sustantivo) de aquellos que ejercen una actividad que -como veíamos- asimismo tal vez cabría en sentido amplio adjetivar de trabajo intelectual: esas dos categorías -dice- no coinciden y sobre todo los problemas que les incumben son profundamente diversos. No coinciden ya que, si es verdad que un intelectual realiza un trabajo no manual, también lo es que no todos los que realizan un trabajo no manual son intelectuales. Lo que en definitiva define/describe para Bobbio la función del intelectual, de todo intelectual, junto a esas otras decisivas tareas básicas de estudio, de conocimiento y de consideración de efectos sociales, es -añade, con carácter genérico, aquél- la de suministrar o proponer criterios-guía, es decir valores, principios, fines, ideales, concepciones del mundo que repercutan de un modo u otro sobre la realidad social. Estos serían los “intelectuales-filósofos”, diferenciados pero interrelacionados con los que califica de “intelectuales-técnicos”: los primeros son quienes sugieren, para bien o para mal, esos principios-guía, o sea conocimientos de fines (muy diversos e, incluso, opuestos como ya vimos), mientras que los segundos, los expertos, ante todo suministrarían métodos, o sea conocimientos de medios para avanzar hacia tales fines ${ }^{4}$.

Un tanto extrañamente y sin mayores explicaciones ni tampoco -creo- implicaciones, Bobbio califica también a los intelectuales-filósofos de "ideólogos" (pero en sentido descriptivo, no en el valorativo-negativo de Marx, referida la ideología a la distorsión del conocimiento, a la deformación de la conciencia). Y así escribirá que los ideólogos son quienes elaboran los principios en base a los cuales una acción se dice racional en cuanto sea conforme con ciertos valores propuestos como fines a conseguir; por su parte, los expertos serían así quienes, presentando los conocimientos más aptos para llegar a un fin, permiten que la acción que se adecua a él pueda calificarse de racional respecto a ese fin. La diferencia entre unos y otros puede ser interpretada -señala Bobbio- mediante la distinción weberiana entre acciones racionales en atención a valores y acciones racionales

\footnotetext{
${ }^{4}$ Expresamente reenvía Bobbio sobre esta cuestión de fines y medios a las conocidas obras de Raymond Aron, L'opium des intellectuels (1955) -para Aron ese opio es el comunismo, recuerda Bobbio- y de G.P. Prandstraller, L'intellettuale-tecnico e altri saggi (1972).
} 
en atención a fines. Pero tras la diferenciación viene enseguida, como debe ser y como es habitual en él, la relación ineludible entre ambas dimensiones. Como ocurre siempre, también en estas cuestiones -dirá- la realidad social es más complicada que las categorías que adoptamos para dominarla mentalmente: no hay ideólogo que no pida ayuda coherente a los conocimientos técnicos y no hay experto que no deba tener alguna idea de los fines para dar sentido a sus análisis 5 .

3.- Dentro de la complejidad y la fluidez de todo cuanto intenta entender lo que es real (y racional), relativamente claro y firme -espero- todo lo anterior, es decir la no confusión entre una definición descriptiva (qué es y quien es intelectual) y una definición prescriptiva (que debe ser y hacer el intelectual), Norberto Bobbio reivindica siempre como fundamental esta segunda dimensión, es decir la no inhibición de la prescripción. Insistirá desde ahí en que la principal función del intelectual, junto a describir también qué son y qué es lo que ellos hacen, ha de ser sobre todo y de manera muy decisiva la de señalar que es lo que a juicio de cada cual los intelectuales debieran ser y hacer. Describir hechos pero también, más específicamente, prescribir valores: y eso vale para toda su filosofía (jurídica y política). Por supuesto que, para él, tal propuesta y su consiguiente contenido prescriptivo no poseen para nada carácter dogmático, ni es nunca una certidumbre cerrada y acabada. Nada más lejano de Bobbio que un cierto tipo de intelectual (filósofo, científico social, clérigo, periodista o lo que sea) oráculo siempre infalible y absolutamente omnisciente. Por el contrario, su modelo del "intelectual mediador" -ya lo veíamos- se construye siempre sobre la duda, la perplejidad, la comprensión de los otros, la tolerancia, el diálogo y la comunicación. Pero, a su vez, es bien cierto que desde ahí -desde il dubbio- Bobbio no renuncia nunca a la scelta, la opción, la elección racional y en libertad que ayude para mejor a las decisiones y resoluciones colectivas.

¿Cómo se distingue -pregunta aquél- la civilización de la barbarie, el progreso de la decadencia, los adelantos y las mejoras individuales y colectivas respecto de los retrocesos y las regresiones? Precisamente -se-

\footnotetext{
${ }^{5}$ Señala Bobbio que la mejor ilustración sobre estas dos figuras de intelectuales está -a su juicio- en dos libros fundamentales: La trahison des clers (1927) de Julien Benda y American Power and the New Mandarins (1970) de Noam Chomsky. Los intelectuales traidores de que habla Benda los filósofos (ideólogos) del irracionalismo, entre otros los doctrinarios que dieron origen y apoyo a la reaccionaria Action française y a sus antidemocráticas y totalitarias derivaciones posteriores; por su parte, como es bien sabido, a quienes ataca duramente Chomsky (los nuevos mandarines) son los llamados “intelectuales-expertos”, técnicos, científicos, sociólogos, economistas que a través de su mayor supuesta competencia profesional -dice- contribuyeron fuertemente a la prosecución y agudización entonces de la guerra de Vietnam (hoy podría todo ello trasladarse a la guerra de Irak).
} 
ñala aquél- es aquí donde, entre otras, se situaría la tarea de la cultura y la función del intelectual: elegir los fines y, tras haberlos debatido y elegido, procurar contribuir a orientar la vida social y política de cada tiempo hacia dichos objetivos. En este punto habría que subrayar -me parece importante- que la particular actitud prescriptiva y optativa de Bobbio como intelectual, como hombre de cultura, está firmemente radicada en los propios factores (y valores) básicos que hacen posible, más fiable y segura, la misma vida intelectual, la existencia y subsistencia de la cultura: estudio, razón, pluralidad crítica y libertad para discrepar, diálogo con la comunidad científica etc. Anota así de manera correlativa que a los hombres de cultura les corresponde una tarea eminente en defensa de las condiciones mínimas que permitan la supervivencia y el desarrollo del mundo civil; y, unida a ella, el compromiso/responsabilidad de actuar para la defensa de las condiciones mismas y los postulados básicos de la cultura.

La defensa y fortalecimiento de esas condiciones que permitan la supervivencia y el desarrollo de la misma sociedad civil y de los postulados básicos de la propia cultura -casi imprescindibles para todo intelectual (y para todo ciudadano)- son las que están detrás del proyecto ilustrado autocrítico en el que, en sus caracteres genéricos y más decisivos, yo situaría el pensamiento de Norberto Bobbio. Y ello desde su inicial neo-iluminismo entendido -de acuerdo aquél con la conceptualización hecha por Nicola Abbagnano- como "la filosofía que, a través de los instrumentos cada vez más refinados y eficaces que el progreso de la ciencia pone a disposición de los hombres de acción, guía el pensamiento abstracto hacia el estudio de los problemas muy concretos de la reforma de la sociedad”6. Reformismo social y también político, pero hay reformas que sólo consolidan el "sistema” y hay reformas que también ayudan a transformarlo. Desde ahí, la biografía personal e intelectual de Norberto Bobbio, su filosofía política, le conduciría a posiciones sobre las que hay casi general consenso en calificar como muy concordes con un denominado socialismo liberal. O -como yo más bien puntualizaría, entre otras cosas, por su insistencia en la importancia de la igualdad y de la presencia del Estado- más identificadas con lo mejor de la social-democracia y, sin entrar aquí y ahora en mayores diferenciaciones, con el propio socialismo democrático. Se trataría en cualquier caso de una derivación y profundación del mejor liberalismo -“socialista a fuer de libe-

\footnotetext{
${ }^{6}$ Estas básicas puntualizaciones y las del párrafo anterior están textualmente tomadas de ideas suyas de siempre que Bobbio vuelve a evocar en ese último trabajo suyo sobre los intelectuales (1997, pp. 12 y 14), trabajo ya mencionado aquí antes en la nota segunda.
} 
ral”, como se reitera en nuestro país- y no de una "tercera vía” entre aquel y el, entonces, comunismo real ${ }^{7}$.

En ese largo y fructífero itinerario me parece de gran interés resaltar para el sentido de esa evolución lo que él mismo escribía en su ensayo sobre Política y cultura, de 1962. Hoy -señalaba aquél- estamos en disposición de marcar algunos puntos firmes sobre el curso de la humanidad y, a la vez, sobre las tareas de la cultura en torno a los cuales- afirma con algún exceso de optimismo el pesimista Bobbio- estamos todos de acuerdo. Son tres fundamentalmente: ante todo el universalismo, es decir la comprensión de la humanidad como sociedad universal. Ello le lleva -coherente con lo mejor de la Ilustración- a una cultura que se inspira en valores universales, para nada dogmáticos ni ahistóricos. En segundo lugar -señala aquél- el igualitarismo. "Hay -afirma- en la historia humana una vocación profunda hacia la igualdad, entendida como eliminación o disminución de las distancias entre hombre y hombre, entre clase y clase, entre pueblo y pueblo"; se trata, pues, del descubrimiento de la substancial igualdad entre todos los seres humanos, hacia la cual Bobbio tenía siempre muy especial sensibilidad. Y también -tercer punto firme- el personalismo: anotaré por mi cuenta que me parece bastante mejor esta denominación propuesta por él, dentro de ese contexto (la cual no es exclusiva de culturas católicas, como a veces se reclama), que la del antisocialista individualismo que con tan machacona insistencia se predica y se hace imponer en el mundo actual. Con ese personalismo -dice Bobbio- se indica la tendencia a considerar al ser humano como fin en si mismo y siempre en libertad. La cultura vive y se desenvuelve solamente en libertad; pero -haría observar yo- también puede surgir y luchar contra su negación en situaciones de dictadura y de opresión; una política de la cultura no puede dejar de ser por ello una política para la libertad. No hay -añade aquél- peor enemigo de la cultura que el conformismo, la docilidad hacia los poderosos, la condescendencia con las consignas de la política. Por decirlo -concluye Bobbio- con una fórmula que sirva como resumen: "no hay verdad sin libertad”.

Universalismo, igualitarismo, personalismo, cultura de la libertad, democracia, espíritu laico, espíritu crítico, lucha por los derechos humanos son -creo- los fundamentos de la filosofía política (y jurídica) de Norberto

\footnotetext{
${ }^{7}$ Para esa insistencia en la igualdad como rasgo definitorio de las posiciones de la izquierda social y política, véase su libro Destra e sinistra. Ragioni e significati di una distinzione politica, Roma, Donzelli Editore, 1994 (Traducción española de Alessandra Picone con Prólogo de Joaquín Estefania, en nueva edición revisada y ampliada con una respuesta a los críticos, Madrid, Taurus, 1995). También los dos trabajos de aquél reunidos, en traducción de Pedro Aragón, en el libro Igualdad y libertad, Introducción de Gregorio Peces-Barba, Barcelona, Ediciones Paidós, 1993.
} 
Bobbio ${ }^{8}$. Democracia y libertad que a pesar de las "promesas no cumplidas" por aquella, a pesar de todas las corrupciones, decepciones, insuficiencias e incomprensiones- van a acercarle y mantenerle de por vida, como vengo diciendo, en la estela de los mejores ideales socialistas. No hay lugar aquí y ahora para volver -lo he hecho en otros escritos míos antes citados- a una más detenida exposición de ese su pensamiento político. Sólo querría recordar algunas palabras suyas, no palabras en vano sino muy sentidas, que, creo poder decir, sus amigos y discípulos le escuchábamos con unos u otros matices hasta el final. Las de afirmar, por ejemplo, que la única vía de salvación es el desarrollo de las condiciones de la democracia hacia aquella participación en los bienes económicos (pero también en los inmateriales) por parte de todos y su distribución más igualitaria: de modo que no puedan ya existir ni, por un lado, esos grandes omnipotentes superpoderes ni, por otro, esas situaciones de degradación humana en amplios colectivos, de reducción de muchos de ellos a "subhombres”, privados de todos sus derechos y libertades. A esa vía democrática y de control de los bienes es -concluía Bobbio- a lo que llamamos socialismo.

Y este, inescindible de la democracia, es -dirá explícitamente aquél- algo todavía por inventar: frente a la pérdida de credibilidad primero y al hundimiento total, después, del denominado socialismo real, frente a su vez a esa determinista dominación del conservadurismo neoliberal en el mundo actual, el socialismo liberal y democrático se ve por él no como algo ya del pasado sino, más bien, como ineludible tarea para el futuro. Y en esa invención, tomada en serio, en esa plural y abierta construcción, me parece con nuestro amigo y maestro que, junto a todos los ciudadanos, una buena parte

\footnotetext{
${ }^{8}$ Para estas y otras dimensiones de su filosofía política, se facilitará la consulta reenviando por de pronto a dos amplias antologías de aquélla: Norberto Bobbio: el filósofo y la política, Estudio preliminar (pp. 13-52) y compilación de José Fernández Santillán, México, Fondo de Cultura Económica, 1996 (576 pp.); y Norberto Bobbio, Teoria generale della politica, edición con introducción (pp. IX-LXX) y muy útil Índice analítico (pp. 649-676) y de nombres, preparada por Michelangelo Bovero, Turín, Einaudi, 1999 (pp. 684). Junto a ellas, entre otros trabajos en español, los contenidos en la obra colectiva La figura y el pensamiento de Norberto Bobbio, Edición de Ángel Llamas, Universidad Carlos III y Boletín Oficial del Estado, Madrid, 1994 (resultado del Curso dirigido por Gregorio Peces-Barba en la Universidad Internacional Menéndez Pelayo de Santander en el verano de 1992); recordaría asimismo los dos artículos sobre Norberto Bobbio recogidos en mi libro Los viejos maestros. La reconstrucción de la razón, Madrid, Alianza Editorial, 1994; y los de Alfonso Ruiz Miguel en Política, Historia y Derecho en Norberto Bobbio, México, Fontamara, 1994; o la obra de Andrea Greppi, derivada de su excelente tesis doctoral, Teoría e ideología en el pensamiento político de Norberto Bobbio, con prólogo del propio Bobbio, Madrid, Marcial Pons Editor, 1998; también finalmente (2005) el libro de Agustín Squella ya mencionado aquí antes en la nota primera. Entre la inabarcable bibliografía italiana y de otros países, mencionaré únicamente entre las últimas publicaciones el colectivo Bobbio ad uso di amici e nemici, al cuidado de la revista "Reset” y de Corrado Ocone, postfacio de Giuliano Amato, Venezia, Marsilio Editori, 2003.
} 
del trabajo corresponderá, hoy y siempre, a los intelectuales, a la responsabilidad del intelectual.

Para ese trabajo hay -creo- buena orientación en la filosofía política y jurídica de Norberto Bobbio en la línea de un explícito reconocimiento de la función del Estado y de un adecuado control a través de su formulación como Estado de Derecho. El único monopolio que corresponde al Estado es el monopolio legítimo de la fuerza y siempre será mejor -advierte aquél en esa vía más proclive al socialismo democrático- una sola fuerza pública que tantas fuerzas privadas en confrontación entre sí: y en confrontación con el Estado. En un escrito sobre Norberto Bobbio y el socialismo liberal, Giuliano Amato resalta que en la actualidad el poder político, constreñido, casi aplastado, entre el poder económico y el poder mediático, se expone a sobrevivir sólo y únicamente en cuanto mera derivada de aquellos. Se trata, pues, del poder político y de los otros poderes (económicos, militares, mediáticos, religiosos, etc.), con frecuencia los transnacionales tanto o más poderosos que aquél y, desde luego, infinitamente más que los anónimos y numerosísimos agentes sin poder 9 .

Norberto Bobbio siempre estuvo enfrente del monopolio absoluto (totalitario, dictatorial) del poder y a favor de distribuir y compartir poderes en contextos de democracia y libertad, a fin de evitar esos grandes omnipotentes superpoderes y, como resultado, esas situaciones de degradación personal y de negación de los derechos humanos. Consciente de las limitaciones, incluso escéptico y pesimista ante los resultados efectivos de esa lucha, sin embargo siempre insistió en que, a pesar de todo, la primera y principal tarea de los intelectuales es y debe ser precisamente la de impedir que el monopolio de la fuerza se convierta también en monopolio de la verdad. En cuanto intelectuales, gentes de la cultura, no sé si se puede hacer mucho contra el monopolio (u oligopolio) de la fuerza, del poder. Pero sí creo que, con la ayuda de hombres como Norberto Bobbio, se puede hacer algo contra el monopolio de la verdad. Él, sabemos, siempre luchó por ello ${ }^{10}$.

\footnotetext{
${ }^{9}$ Esas palabras de G. Amato están en la p. 211 de su postfacio a la obra colectiva sobre Norberto Bobbio citada aquí en las últimas líneas de la nota anterior.

${ }^{10}$ En varios trabajos míos y en concreto en el escrito en recuerdo y homenaje tras su muerte (Norberto Bobbio: memoria española, “Sistema”, 181, julio de 2004) he resaltado algunos de los importantes apoyos que él, siempre con el impulso del también gran amigo y maestro Renato Treves, otorgaron a la oposición democrática de los intelectuales frente a las discriminaciones y persecuciones de la dictadura franquista: precisamente para evitar que aquél monopolio ilegítimo de la fuerza se convirtiera asimismo, como pretendía, en monopolio dogmático de la verdad. (Más, sobre ello, en mi ya citado libro Los viejos maestros. La reconstrucción de la razón, entre otras, pp. 114 y 129; también en mi último libro Un itinerario intelectual. De filosofía jurídica y política, Madrid, Biblioteca Nueva, 2003).
} 
$\triangle \quad$ DOXA 28 (2005) 